\title{
Estereótipos de gênero e apelos retóricos no design gráfico: um modelo de análise
}

\section{Gender stereotypes and rhetorical appeals in graphic design: a model of analysis}

\author{
Bianca Mendes Rati \\ biancamrati@gmail.com \\ Marcos Namba Beccari \\ contato@marcosbeccari.com
}

\section{Resumo}

Este artigo, baseado no trabalho de conclusão de curso homônimo, discorre a respeito das questões relacionadas a gênero em nossa sociedade, bem como sobre qual a relação do design gráfico com essas questões. Delineia-se o design como manifestação da linguagem que utiliza artifícios retóricos como ethos, logos e pathos em sua concepção para transmitir conceitos e se comunicar. Propõe-se então um modelo de análise com o objetivo de verificar as estratégias retóricas visuais utilizadas em peças de design gráfico que tenham recorte de gênero, e como elas traduzem ou não estereótipos da categoria que representam - no caso deste trabalho, focouse nas peças voltadas ao público feminino.

Palavras-chave: Design gráfico, gênero, retórica, modelo analítico

\begin{abstract}
This article, based on homonym work of course conclusion, discusses gender issues in our society, as well as on the relationship between graphic design and these issues. Design is defined as a manifestation of language that uses rhetorical artifices such as ethos, logos and pathos in its conception to transmit concepts and it's communicated. It is proposed a model of analysis in order to verify the visual rhetorical strategies used in graphic design pieces that have a gender target, and how it translates or not stereotypes of the category it represents - in the case of this work, the focus is on the pieces aimed at the female audience.
\end{abstract}

Keywords: Graphic design, gender, rethoric, analysis model 


\section{Introdução}

Este artigo baseia-se no trabalho de conclusão de curso homônimo, realizado em 2017 no curso de Design Gráfico da Universidade Federal do Paraná, e visa apresentar um modelo analítico que relaciona elementos da retórica com questões de gênero.

As questões das mulheres na sociedade têm sido debatidas há muito tempo, mas o uso do termo gênero ganhou destaque nas décadas de 1960 e 1970, com a chamada Segunda Onda do Feminismo. Gênero diz respeito às diferenças sociais, culturais e assimétricas que se constroem a partir da diferenciação sexual biológica, ditando aquilo que é considerado como masculino ou feminino. A ideia de usar esse vocábulo em vez de "sexo" para abordar o tema visa rejeitar a noção de um determinismo biológico e considerar o aspecto político da discussão (LOURO, 2014).

Vivemos numa sociedade de matriz binária quanto a gênero, com funções sociais delimitadas, restritivas e hierárquicas (BUTLER, 2017) que colocam a mulher numa posição social inferior aos homens. A reflexão, a respeito de gênero, não é apenas sobre os papéis socialmente atribuídos a homens e mulheres em determinado contexto, porque isso restringiria as opressões num âmbito de relações interpessoais, deixando de lado as complexas estruturas discursivas de poder que se estabelecem de maneira institucional e simbólica, através de hábitos, costumes, códigos normativos, etc. Com efeito, parte-se da premissa de que as instituições da sociedade são estruturalmente generificadas, ou seja, constituem e são constituintes da identidade de gênero (LOURO, 2014).

$\mathrm{Na}$ atividade de design se dá o manuseio e a construção de discursos, pois o profissional trabalha com conceitos e contextos socioculturais de modo a articular processos de significação em suas peças (SOUZA LEITE, 1996). O projeto de design, enquanto manifestação de linguagem, não é neutro (ALMEIDA JUNIOR; NOJIMA, 2010) e consiste em um jogo de subjetividade e objetividade, onde o designer precisa manipular os discursos, gerando um processo de significação (SOUZA LEITE, 1996). Dessa forma se delineia o papel social do designer gráfico, que, através de seus projetos, busca influenciar atitudes, conhecimentos e o comportamento dos indivíduos (FRASCARA, 2000).

O designer, ao projetar, utiliza elementos visuais para transmitir uma mensagem, os quais podem ser selecionados de várias formas, porém na maioria das vezes privilegia-se o público-alvo da peça. Assim, tais elementos são escolhidos com base em quem se quer atingir. Ao fazer essas escolhas, o designer serve-se de várias técnicas, entre as quais a retórica (ALMEIDA JUNIOR; NOJIMA, 2010).

Ao pensarmos em gênero como identidade, e no design como produção de ordem não somente estética, mas também simbólico-discursiva, torna-se imprescindível levantar a questão de como essas áreas se relacionam (CAMPOS et. al., 2010). Com efeito, verificar como se dá o uso da retórica em peças de design gráfico pode indicar os caminhos deliberadamente traçados para atingir um público específico (neste caso, feminino), e também oferecer uma base para trabalhos que questionem esses caminhos, com propostas inovadoras e menos estereotipadas.

Apesar de design e gênero se relacionarem em muitos momentos, há, de um lado, pouca literatura sobre o tema, sobretudo em português e na área do design gráfico. De outro, muitas vezes os projetos são concebidos considerando apenas a demanda um público específico, portanto dentro de uma perspectiva mercadológica e sem levar em consideração os efeitos discursivos desse artefato na sociedade. Por isso, um modelo analítico pode dar suporte e fomentar a discussão sobre essas questões a partir dos espaços acadêmicos. Observar os padrões (que às vezes podem ser nocivos) também é importante para a produção de um design gráfico efetivamente inovador e articulado com o tempo e a cultura sempre em transformação (KISTMANN, 2014).

Nesse sentido, mostra-se pertinente a proposição de um modelo analítico que evidencie esses pontos. Considerando que as dimensões de gênero e também da retórica no design gráfico são muito vastas, não é a intenção deste trabalho unificá-las de maneira definitiva, mas propor um diálogo estruturado, uma forma de relacioná-las, visando contribuir com a reflexão sobre a responsabilidade que nós, designers, Estudos em Design | Revista (online). Rio de Janeiro: v. 28 | n. 1 [2020], p. 06 - 26 | ISSN 1983-196X 
carregamos ao fazermos escolhas e ao utilizarmos certas estratégias na construção visual de peças de design gráfico, em seu impacto discursivo na sociedade.

Com isso em vista, a primeira parte deste artigo discorre sobre gênero e sua relação com design, bem como a respeito de linguagem visual e retórica, conceitos esses que contituem a fundamentação teórica para o desenvolvimento do modelo. Na sequência, delineia-se o método utilizado para o desenvolvimento do modelo analítico. Uma vez feita a proposição do modelo, segue-se para um breve relato da aplicação-teste realizada, cujos principais resultados e desdobramentos possíveis compõem as considerações finais deste artigo.

\section{Fundamentação Teórica}

\section{Gênero}

As questões de gênero, no presente estudo, foram observadas a partir do panorama histórico apresentado por Alves e Pitanguy (1985) a respeito da história do feminismo, aprofundado pelas reflexões de Louro (2014) e de Butler (2017).

Gênero é um termo que ganhou destaque nas décadas de 1960 e 1970 e diz respeito às diferenças sociais, culturais e assimétricas que se constroem a partir da diferenciação sexual biológica, ditando aquilo que é considerado como masculino ou feminino. A escolha de usar tal vocábulo em vez de "sexo" para abordar o tema visa rejeitar a noção de um determinismo biológico e considerar o aspecto político da discussão (LOURO, 2014).

Louro (2014) afirma que não são as características sexuais e sim a forma que elas são representadas ou valorizadas que determina o que, em uma sociedade, é feminino ou masculino. A autora complementa que, para além da delimitação de papéis sociais, gênero é constituinte da identidade do sujeito: muito mais que se comportar de determinada maneira, há um processo social de identificação. Dessa forma, diversas instituições e estruturas são construtoras de gêneros e construídas por eles.

Para Alves e Pitanguy (1985), existe uma hierarquização onde o masculino é considerado superior e o feminino, inferior, ideologia transmitida desde cedo pelas instituições formadoras como escola, família, comunicação, religião etc. Nesse sentido, há uma naturalização não somente de papéis ou estigmas, mas também de ideologias e estruturas sociais binariamente generificadas que são histórica e culturalmente atravessadas pelo gênero (LOURO, 2014).

A generificação acontece em diversas áreas e escalas: justiça, igreja, governo, educação, relações interpessoais, cultura etc., e existem inúmeras dimensões em que a naturalização heteronormativa hierarquizada de gêneros produz opressão. A violência física é um exemplo, juntamente com as violências morais e psicológicas, como ridicularização, intimidação, desvalorização cotidiana das mulheres e de sua capacidade intelectual, entre outras inúmeras manifestações (SEGATO, 2003).

Já na esfera cultural, podemos observar violência e desigualdade de gênero em hábitos e discursos historicamente mais aceitos, o que repercute e é reproduzido nos produtos culturais, nas representações imagéticas e nas expressões midiáticas. Ortner (1974) argumenta que há um pensamento amplamente difundido que associa as mulheres - seus corpos, papéis sociais e comportamentos - à natureza, e os homens à cultura (natureza transformada, manufaturada). Devido à suposta função de procriação dos corpos femininos, as mulheres estariam envolvidas mais diretamente com a manutenção da espécie e em constante contato com seu "lado animal" (através do ciclo menstrual e seus desdobramentos), ao contrário dos homens. Esse pressuposto tende a legitimar uma liberdade maior aos homens para "tomarem conta" de projetos culturais. 
Ainda a respeito de estereótipos de gênero, Amâncio (1992, p. 10) sublinha que os traços de "[...] instrumentalidade, independência e dominância" são considerados masculinos, enquanto "[...] expressividade, dependência e submissão" são tidos como femininos. Segundo a autora esses ideais aparecem até mesmo em estudos transculturais e representam uma expectativa comportamental para cada gênero, o que acaba por restringir os espaços das mulheres.

\section{OS ESTEREÓTIPOS SEXUAIS}

\begin{tabular}{|llll|}
\hline Afectuosa & $\mathrm{F}+$ & Feminina & $\mathrm{F}$ \\
Ambicioso & $\mathrm{M}$ & Forte & $\mathrm{M}+$ \\
Audacioso & $\mathrm{M}+$ & Frágil & $\mathrm{F}$ \\
Autoritário & $\mathrm{M}$ & Independente & $\mathrm{M}+$ \\
Aventureiro & $\mathrm{M}$ & Machista & $\mathrm{M}$ \\
Bonita & $\mathrm{F}+$ & Maternal & $\mathrm{F}$ \\
Carinhosa & $\mathrm{F}+$ & Meiga & $\mathrm{F}+$ \\
Corajoso & $\mathrm{M}+$ & Paternalista & $\mathrm{M}$ \\
Dependente & $\mathrm{F}-$ & Rígido & $\mathrm{M}$ \\
Desinibido & $\mathrm{M}+$ & Romântica & $\mathrm{F}$ \\
Desorganizado & $\mathrm{M}-$ & Sensivel & $\mathrm{F}+$ \\
Dominador & $\mathrm{M}-$ & Sentimental & $\mathrm{F}$ \\
Elegante & $\mathrm{F}+$ & Sério & $\mathrm{M}+$ \\
Emotiva & $\mathrm{F}$ & Submissa & $\mathrm{F}-$ \\
Empreendedor & $\mathrm{M}+$ & Superior & $\mathrm{M}$ \\
& & Viril & $\mathrm{M}$ \\
\hline
\end{tabular}

Figura 1: Quadro - Os estereótipos sexuais. Fonte: Amâncio, 1992, p. 14.

Amâncio (1992) apresenta uma pesquisa realizada na década de 1990 com 182 pessoas que visava verificar a existência e força dos estereótipos sexuais, além de demonstrar a assimetria que os transpassa. Na Figura 1, abaixo, estão descritas algumas palavras que foram consenso entre os entrevistados a respeito de características femininas $(\mathrm{F})$ ou masculinas $(\mathrm{M})$; também foi solicitado à metade dos participantes que eles classificassem esses traços como positivos (+) ou negativos (-) para um adulto. Nota-se, através dessa pesquisa, que existem menos características atribuídas às mulheres do que aos homens, e também que há mais traços tipicamente femininos associados negativamente (AMÂNCIO, 1992).

Os estudos de gênero mostram as facetas das desigualdades - econômicas, políticas, sociais e culturais - entre homens e mulheres e trazem diversas questões importantes a serem observadas por todas as áreas do conhecimento e comportamento humano, deixando clara a necessidade de desconstruções de paradigmas a respeito dos papéis sociais femininos e da noção de feminilidade como um todo. Apesar de existirem diversas abordagens acadêmicas que problematizam gênero, ainda resta um campo vasto onde essa questão pode ser levada em consideração.

\section{Design e gênero}

O processo de design envolve suprir alguma necessidade de um usuário, necessidade esta a ser atendida por uma solução gráfica, um artefato, um service, ou outro processo elaborado pelo designer. Para tanto, leva-se em consideração um conjunto de valores socioculturais com os quais esse usuário se identifica e, após um processo de estudo e decodificação desses valores e necessidades, elabora-se determinado produto cultural (CAMPOS; LEITE; WAECHTER, 2010).

Campos, Leite e Waechter (2010) destacam o caráter comunicacional desses produtos culturais, que fazem parte de um sistema de comunicação determinado pela linguagem visual e seus elementos compositivos. Ono (2006, p. 47) discorre sobre a relação dinâmica entre os objetos e a sociedade, cabendo ao designer interpretar as "[...] funções e significados em que as percepções, ações e relações se entrelaçam no contexto de espaço e tempo em que se inserem". Deste modo, o designer, se não tiver 
o devido cuidado crítico, acaba reproduzindo inconscientemente estereótipos, comportamentos, estilos de vida ou outros valores intangíveis da cultura.

Em meados dos anos 1950, e a partir de projetos voltados para o usuário, ganhou força a percepção da influência ativa dos bens de consumo adquiridos por um indivíduo na construção de sua identidade. Acredita-se, portanto, que é a partir deste momento que a pretensão de que o consumidor se idenfique com seus produtos passou a ser parte do projeto de design. Isso signifca que os os produtos não devem atender apenas a funções práticas, mas devem atender também a funções estético-simbólicas cujas representações enviam mensagens comunicativas que excedem aquilo que apresentam, especialmente no que se refere a status, classe, gênero e identidade (CAMPOS LEITE; WAECHTER, 2010, p. 4).

Como visto, gênero é uma identidade que, junto com várias outras, constituem os sujeitos (LOURO, 2014). Já as produções dos designers possuem discursos codificados pela linguagem visual - mesmo não intencionais - que visam comunicar e gerar identificação no usuário. A questão levantada diz respeito a quais discursos acerca de gênero e feminilidade têm sido reproduzidos através do design e quais efeitos esses discursos geram na sociedade.

Campos, Leite e Waechter (2010) discorrem a respeito das perspectivas que podem ser usadas para pensar a questão de gênero no design. Uma delas é a partir da invisibilidade histórica das mulheres no design, ao passo que os trabalhos feitos por homens são citados e valorizados. A outra se refere a certa limitação metodológica: ou o designer reproduz seus preconceitos de gênero sobre o projeto, ou não dá importância para a questão. Por conseguinte, acaba contribuindo para a perpetuação de estereótipos sexistas e culturalmente enraizados, muitas vezes deixando de levar em conta as necessidades reais de seus usuários e da sociedade como um todo.

$\mathrm{Na}$ perspectiva histórica, a contribuição de Buckley (1986) mostra como o patriarcado ${ }^{1}$ e o capitalismo influenciam as relações entre o design e as mulheres. Ela descreve o modo como, historicamente, devido ao patriarcado, as mulheres estiveram impedidas de participar integralmente de todas as áreas da sociedade - e, portanto, também do design. Isso restringiu seus espaços de atuação, de tal modo que elas só adentravam campos diferentes do que se esperava delas: se estivessem envolvidas na criação de produtos voltados principalmente para casa, "conheceriam melhor" esse ambiente, algo interessante para uma perspectiva capitalista.

Desse modo, o design tem se baseado, muitas vezes, em paradigmas patriarcais e sexistas, desenvolvendo peças reprodutoras desses discursos. Nota-se também que, paralelamente, a ausência histórica de mulheres no design debilita a desconstrução desses mesmos discursos, pois resulta de uma falta de representatividade feminina.

Barnard (2005) mostra como é abordado gênero em embalagens; neste caso, embalagens de lâminas de barbear e de depilação. O autor observa o uso da cor, da forma, da linha e da tipografia como construtores e comunicadores da identidade de gênero.

\footnotetext{
${ }^{1}$ Segundo Buckley (1986), o conceito de patriarcado tem sido definido e repensado por várias feministas ao longo da história. A definição que ela utiliza para fundamentar seu artigo é a que a autora Griselda Pollock desenvolve em "Vision, Voice and Power" (1981), que considera patriarcado não apenas como a dominação estática opressiva de um sexo sobre o outro, mas também como uma "teia de relacionamentos psico-sociais" que instituem uma diferença significativa no eixo do sexo, que está profundamente enraizado em nosso sentido de identidade sexual, vivido de forma a ser naturalizado.
} 

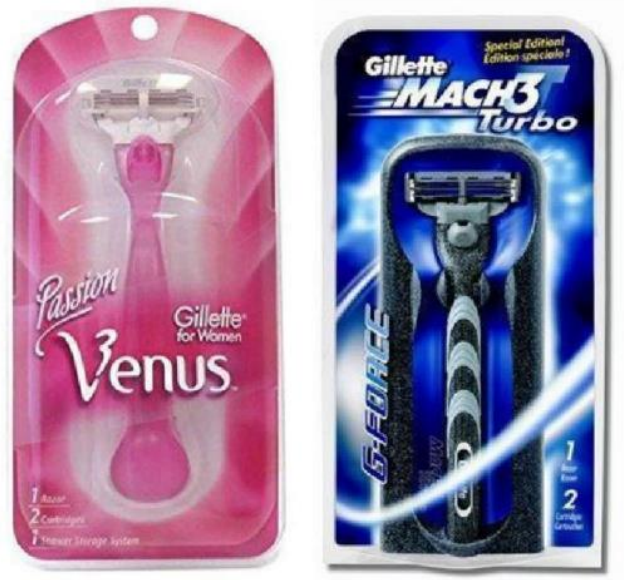

Figura 2 (esquerda): Gillette Venus. Fonte: https://goo.gl/xhwNRr. Acesso em 02 mai. 2017.

Figura 3 (direita): Gillette Mach3 Turbo. Fonte: https://goo.gl/j13PMo. Acesso em 02 mai. 2017.

Na embalagem da lâmina feminina chamada "Vênus" (Figura 2), por exemplo, as cores disponíveis são azul claro e "passion pink" (rosa paixão); a tipografia do nome é curva, sem serifa, e as formas remetem a uma concha. Já na lâmina masculina "Mach3 Turbo G-Force" (Figura 3), as cores variam entre tons de cinza, preto e azul escuro, e a tipografia é itálica e sem serifa. Barnard aponta como na cultura ocidental rosa é considerada uma cor feminina, e azul, uma cor masculina. Essa diferença aparentamente simples demonstra como dois produtos com funções iguais, por meio do design, definem diferentes identidades de gênero.

Dobson e Dobson (2016) pontuam, em seu artigo, que a sociedade tem se tornado cada vez mais voltada para os símbolos visuais, por isso os designers precisam se conscientizar de sua responsabilidade no impacto gerado por tais artefatos na sociedade. Adotar símbolos que estão ultrapassados e não considerar seus significados aumenta o risco de reforço de conceitos pejorativos.

É pertinente salientar a falta de literatura e discussão de como estereótipos de gênero atravessam outras áreas do design gráfico para além das peças publicitárias. Embalagens, sites, aplicativos, ilustrações, personagens, design da informação, livros e revistas são pouco explorados e pouco observados segundo esse ponto de vista. Apesar de a propaganda configurar uma mídia onde o discurso - a respeito do que é anunciado e de quem é seu consumidor - tende a ser mais explícito, outros aspectos e trabalhos de design também são parte da cultura e, ao mesmo tempo, agentes que a influenciam.

\section{Discurso visual e retórica}

O design gráfico faz uso da linguagem visual para comunicar. Horn (1998) define a linguagem gráfica como a interação entre texto, imagens e formas, compondo uma única unidade de comunicação. No livro Visual Language: Global Communication for the 21st Century, o autor defende que, assim como na linguagem verbal, a linguagem visual também conta com aspectos sintáticos, semânticos e pragmáticos.

Ao se pensar na linguagem gráfica/visual e seus elementos, é preciso observar que eles são atravessados pelo discurso. Foucault (2008) argumenta que os elementos da linguagem não são suficientes para dar conta do significado de um conteúdo, mas que há um conjunto de regras, o discurso, pautando aquilo que pode ou não ser dito, aquilo que é ou não significativo. Essas regras estão ligadas ao conjunto social, cultural e histórico de convenções vigentes que se transformam ao longo do tempo. O discurso define o que é "verdade" e legitima ou deslegitima determinadas ações. "O discurso nada mais é do que um jogo" onde se joga com os signos e tendo o próprio discurso como seu significante (FOUCAULT, 2014, p. 46). 
Foucault (2008), ainda, faz uma separação entre enunciador e conteúdo enunciado, apontando as interações entre os diversos enunciados que podem não ser intencionais ou até mesmo desejados por aquele que produz determinado conteúdo. Uma análise desses enunciados, como proposta pelo filósofo, seria capaz de indicar os "jogos de relações" (discursos) que estão por trás (ou melhor, ao redor) do que fora produzido (FOUCAULT, 2008, p. 32).

A ideia de linguagem visual como gramática autônoma, descolada da subjetividade do designer e da interpretação daquele que vai interagir com a peça, é criticada por Barros (2009). Isso porque o designer tem um papel significativo na construção de discurso, operando como mediador em processos comunicacionais e navegando por um sistema complexo de discursos diferentes que interagem entre si, conforme corrobora Souza Leite (1996).

Levando em conta esse aspecto comunicacional do design gráfico, cumpre mencionar também a perspectiva de Bonsiepe (2011) segundo a qual a comunicação só existe quando há uma retórica que lhe dê forma. Por sua vez, Almeida Júnior e Nojima (2010) afirmam que o próprio design gráfico é um tipo de "manifestação da linguagem" e que o sucesso do trabalho do designer está ligado à construção e à compreensão de significados. Os autores apontam que não existe linguagem neutra, ou seja, não existe linguagem livre de retórica. Desta forma, pode-se falar de uma retórica visual e até mesmo de uma retórica do design gráfico.

Retórica é definida por Reboul (apud Emanuel, 2017, p. 10) como "a arte de persuadir pelo discurso". Emanuel (2017, p. 26) aponta, porém, que há variações de uso sobre o termo ao longo da história: no período clássico pré-aristotélico, retórica dizia respeito à argumentação; posteriormente, com as leis de propriedade se consolidando, as pessoas precisavam de eloquência para defender suas causas, e a retórica passa a ser difundida.

No século XX os princípios retóricos passaram a ser aplicados a objetos de outras áreas, como argumentos visuais, utensílios e produções audiovisuais. Barthes (1977), por exemplo, a fim de analisar se as imagens contêm signos, faz um paralelo entre as linguagens (visual e verbal) e as dinâmicas sociais. $\mathrm{O}$ autor produz uma análise, voltada para imagens publicitárias, chamando de ideologia quando existe o domínio (conhecimento), no interior de uma sociedade e período histórico, de um conjunto de significados. Ele chama de conotadores os significantes de determinada conotação e o conjunto de conotadores constitui a retórica (EMANUEL, 2017).

Em sua tese de 2010, Almeida Junior e Nojima propõem uma retórica do design gráfico. Apoiados pela retórica aristotélica, os autores analisam as ferramentas de persuasão adotadas na composição de capas de revistas. Outros(as) autores(as) também utilizam as premissas retóricas aplicadas ao design gráfico, como Ellen Lupton e Hanno Ehses (1998) no Rhetorical Handbook, mostrando as figuras de linguagem em projetos, e Richard Buchanan (1995) no artigo Rethoric, Humanism and Design, propondo a dimensão retórica como aspecto indissociável de uma concepção humanista de design.

Apesar das variações e diversas utilizações que a retórica adquire no decorrer da história, seu objetivo de influenciar e atingir determinado público se mantém atual. Ao retomarmos os princípios e estratégias da retórica clássica e trazê-los para novos contextos e desdobramentos da linguagem (como o design gráfico), é possível verificar de que maneira eles atuam e podem ser utilizados. Uma possibilidade, estudada neste trabalho, é observar como as provas retóricas ethos, logos e pathos operam no design gráfico ao se endereçarem a um recorte genereficado.

Ethos, Logos e Pathos 
Ethos, Pathos e Logos consistem em provas retóricas, providas pelo discurso, que Aristóteles estudou. Cada uma dessas provas configura um conjunto de estratégias pelas quais o discurso é moldado a fim de atingir seu público. No caso da retórica aplicada ao design gráfico, conforme Emanual (2017) delineia em sua tese de doutorado, pode-se observar que diversas vezes as peças apresentam mais de uma estratégia; porém, para fins didáticos, foram elencados exemplos que se destacam em um ou outro aspecto.

\section{Ethos}

A estratégia do ethos pauta-se na moral do orador, que pode tomar como base sua própria autoridade ou a de outros, utilizando-os como exemplo. Breton (apud EMANUEL, 2017) fala sobre três tipos de autoridade: dada pela competência, pelo testemunho ou pela experiência. A competência tem como base o conhecimento científico, técnico ou profissional, sendo mais teórica do que a experiência, onde o aprendizado vem das atividades práticas e da vivência do orador. Já o testemunho apresenta um caráter mais efêmero, pois trata da presença de alguém em determinada situação.

\begin{tabular}{|c|c|}
\hline & ETHOS \\
\hline APELO & $\begin{array}{c}\text { Credibilidade, tradição, confiança, moral, fidedignidade, } \\
\text { de boa índole, honesto, correto, leal. }\end{array}$ \\
\hline $\begin{array}{l}\text { POSSÍVEIS } \\
\text { APLICAÇÕES }\end{array}$ & $\begin{array}{l}\text { Nome da marca, layout objetivo e limpo, centrado às necessidades do } \\
\text { usuário, formas simples e clássicas, alusão à ciência etc. }\end{array}$ \\
\hline
\end{tabular}

Tabela 1 - Ethos: apelos e aplicações. Fonte: Autores, 2018.

Nessa prova retórica, são as qualidades e a credibilidade do orador que estão em foco. Fogg (apud EMANUEL, 2017) mostra como o design pode influenciar a maneira que interpretamos determinado produto ou serviço como sendo confiável ou não. A página inicial do site de pesquisas Google (Fig. 4) é um bom exemplo de aplicação do ethos, pois em seu layout observa-se o destaque à marca - que atualmente já é usada em muitos países como verbo, o que sinaliza seu sucesso retórico - e o campo de pesquisa em si, mostrando assim os objetivos do site e a preocupação em atender a necessidade do usuário: fazer uma pesquisa (EMANUEL, 2017).

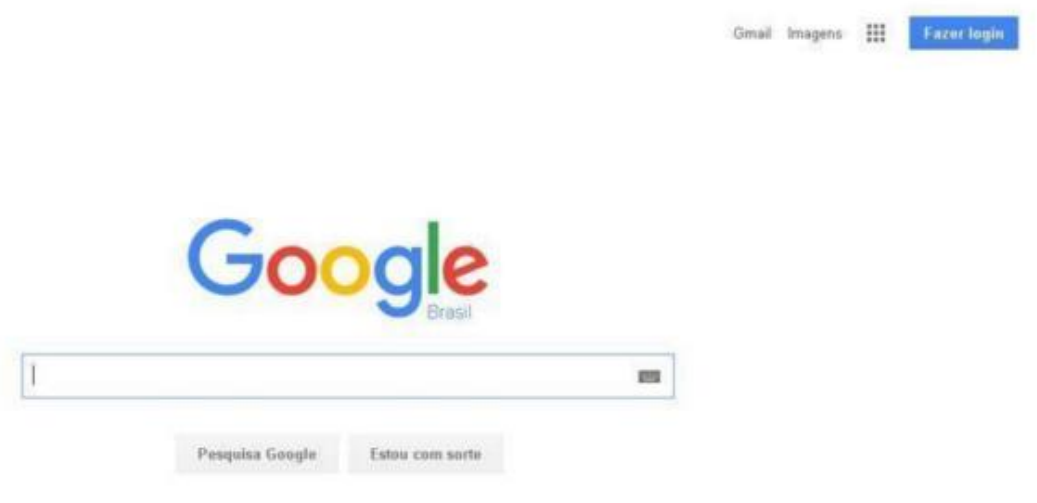

Figura 4: Tela inicial do Google. Fonte: https://goo.gl/2RgttH. Acesso em 06 jun. 2017.

Logos 
Nessa estratégia, a argumentação se dá através de argumentos lógicos. Aristóteles propõe dois tipos de argumentos lógicos: entinema e o exemplo. O primeiro trata de uma hipótese que não é necessariamente verdadeira, mas que é viável, como Emanuel (2017, p. 49) exemplifica na frase: "Esta cidade é perigosa, portanto devemos andar armados". Já o exemplo tenta comprovar a verdade por meio da exposição de casos similares e aplicando suas causas ou consequências à pauta em questão. Também pode ser usado como uma explicação ou esclarecimento ao público (EMANUEL, 2017).

\begin{tabular}{|c|c|}
\hline \multicolumn{2}{|c|}{ LOGOS } \\
\hline APELO & Dedução, causa-consequência, lógica, didatismo, evidência, exemplo. \\
\hline $\begin{array}{c}\text { POSSÍVEIS } \\
\text { APLICAÇÕES }\end{array}$ & Números, proporções, infográficos, esquemas, setas etc. \\
\hline
\end{tabular}

Tabela 2 - Logos: apelos e aplicações. Fonte: Autores, 2018.

Como exemplo de aplicação prática dessa estratégia, aponta-se o caso do logotipo da empresa transportadora norte-americana FedEx (Fig. 5), que tem como promessa a rapidez e a certeza da entrega. $\mathrm{O}$ argumento aparece através da contra-forma entre as letras $\mathrm{E}$ e $\mathrm{X}$, representado por uma flecha direcionada para a direita, indicando movimento, direção, continuidade e velocidade.

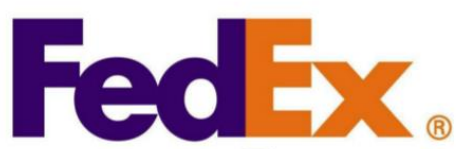

Express

Figura 5: Logotipo da marca FedEx. Fonte: https://goo.gl/ro6LWa. Acesso em: 06 jun. 2017.

Infográficos, assim como a maioria das peças de design gráfico, costumam empregar várias estratégias retóricas ao mesmo tempo, mas a estratégia de logos é bem evidente no caso de representações de informações numéricas, estatísticas e proporções (Fig. 6).

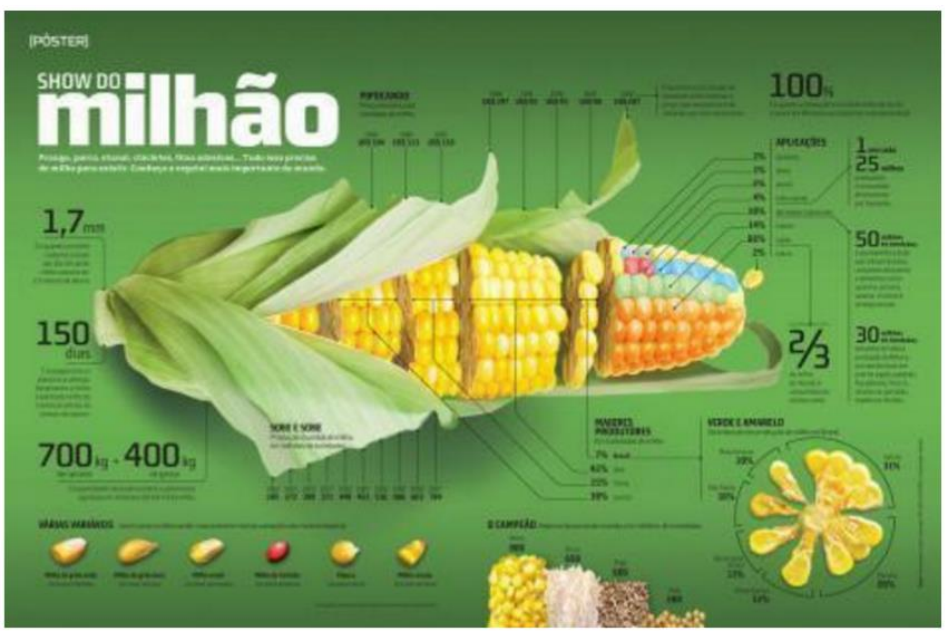

Figura 6: Infográfico Show do Milhão, Revista Super Interessante. Fonte: https://goo.gl/Ex7evQ. Acesso em: 06 jun. 2017. 


\section{Pathos}

Quando a argumentação do orador é de caráter emocional, tentando comover o público, a abordagem utilizada é chamada de pathos. Aristóteles pontua que as pessoas percebem fatos de uma certa maneira ou de outra dependendo do seu estado emocional. Essa sensibilidade comocional pode ser atingida apelando para os possíveis desejos e experiências da audiência (EMANUEL, 2017).

\begin{tabular}{|c|c|}
\hline \multicolumn{2}{|c|}{ PATHOS } \\
\hline APELO & Expectativas, analogias, alusões indiretas, referências, lembranças. \\
\hline $\begin{array}{c}\text { POSSÍVEIS } \\
\text { APLICAÇÕES }\end{array}$ & Mascotes, personagens, texturas, paletas de cores, formas etc. \\
\hline
\end{tabular}

Tabela 3 - Pathos: apelos e aplicações. Fonte: Autores, 2018.

A empatia em relação com a marca pode ser gerada através da figura de um mascote, como ocorre com a famosa marca de pneus Michelin. O personagem ilustrado, que passou por um processo de personificação, torna a marca mais amigável. Outro exemplo da aplicação de pathos reside nos cartazes de filmes de terror, que geralmente são elaborados para gerar uma sensação de medo ou angústia, como se um sujeito transtornado os tivesse feito.

\section{Modelo de Análise}

Partindo dos conceitos estabelecidos na fundamentação teórica, foi possível estabelecer relações entre design, estereótipos de gênero e retórica, considerando que a generificação é carregada no discurso mediado por uma ou mais estratégias retóricas nas peças de design. A partir dessa relação, propõe-se um modelo para analisar como os apelos retóricos são aplicadas no design gráfico de modo a reforçar ou questionar estereótipos de gênero em peças voltadas para o público feminino.

O modelo está estruturado em quatro etapas, sendo elas: seleção, investigação, análise e diagnóstico; cada etapa tem um objetivo e procedimentos específicos, os quais são explicados adiante. Essas etapas foram inspiradas no método clássico científico, sintetizado no anagrama THEOC: teoria, hipótese, experimento, observação e conclusão (DUBBERLY, 2004). A fase da teoria é incorporada no estudo prévio dos conceitos apresentados no modelo; a hipótese, na seleção da peça que o analisador que busca, no modelo, uma verificação de seu argumento; o experimento e a observação, na análise utilizando a participação de usuários (Parte 1), mas também por meio da avaliação do aplicador (Parte 2); por fim, a conclusão configuraria a parte de diagnóstico.

A intenção é que, após terminada a análise proposta pelo modelo, o(a) pesquisador(a) poderá observar se a peça analisada reforça ou não estereótipos relacionados à feminilidade, e qual (ou quais) estratégia retórica aparece predominantemente, de modo a entender o apelo construído a respeito de determinado gênero, neste caso, o feminino. Abaixo, discorre-se sobre cada etapa do modelo e suas especificações.

\section{Seleção}

A primeira etapa refere-se à escolha de uma ou mais amostras, podendo ser de qualquer área de atuação do design gráfico (web, editorial, identidade visual, embalagem etc.), com restrição de públicoalvo por gênero: masculino, feminino, ambos ou outros. Algumas sugestões a serem utilizadas como critério de seleção são:

- linha de produtos ou peças de uma mesma marca ou campanha;

- produtos ou peças de um mesmo segmento, mas de marcas diferentes; 
- peças que tiveram destaque ou notoriedade na mídia;

- peças que foram premiadas em catálogos.

\section{Investigação}

A segunda fase é uma pesquisa nos informativos oficiais da empresa ou instituição para a qual a peça foi desenvolvida e/ou veiculada, a fim de entender o que o design busca traduzir:

- Quais são os seus valores?

- Quais são os conceitos envolvidos no projeto gráfico?

Como visto, o designer sempre leva em consideração, mesmo que inconscientemente, valores socioculturais, estudando-os e decodificando-os em sua atividade criativa a fim de comunicar-se com o público e atender suas necessidades (CAMPOS et. al., 2010).

Geralmente esses dados aparecem nos campos 'missão' e 'visão' dentro dos sites ou em outros materiais de apresentação da empresa, e são importantes para perceber como determinados valores se traduzem, por meio design, na visualidade. Se possível, é importante também buscar informações sobre o projeto gráfico para enriquecer essa etapa de investigação.

\section{Análise}

A terceira etapa se divide em duas partes, uma relacionada aos estereótipos de gênero, e a outra, às estratégias retóricas.

\section{Parte 1: Estereótipos}

Esta fase pretende realizar uma pesquisa com diferentes públicos para verificar suas percepções a respeito das amostras quanto a estereótipos de gênero. A pesquisa deve ocorrer com a aplicação de um formulário no qual as amostras são apresentadas a pessoas de diferentes idades e identidades de gênero. Junto às amostras são elencadas características relativas à estereótipos de gênero, com a solicitação de que os participantes relacionem a amostra às características a que se aplicam, ou que a descrevem.

Por meio desta pesquisa pretende-se observar como as pessoas percebem as peças de design, para além do projeto do designer ou intenção da instituição. As imagens transmitem mensagens de forma intencional ou não e muitas vezes o designer não tem controle de todos os significados, ainda mais quando não considera com atenção as relações discursivas que permeiam os artefatos e símbolos (CAMPOS et. al., 2010).

No questionário, as pessoas devem indicar sua faixa etária e identidade de gênero; a sugestão é que se contemple mais de uma pessoa de determinado gênero e idade, a fim de se coletar mais perspectivas. A partir disso, a amostra é apresentada sem contexto, ou seja, sem explicações a seu respeito, conceitos e ideais, evitando influenciar o espectador em suas respostas.

As características utilizadas no formulário derivam da pesquisa realizada por Lígia Amâncio (1992), que apresenta estereótipos de gênero (Quadro 1), e também da pesquisa de Ortner (1974), que descreve a associação atribuída às mulheres com a natureza e o orgânico. A partir dessas fontes, foram elencadas qualidades que estão descritas na tabela abaixo (Tabela 4). As características aparecem em forma de questão de múltipla-escolha e de modo aleatório (sem distinguir quais características são femininas e masculinas), de modo que os participantes possam selecionar aquelas que fazem sentido para descrever a amostra, ou que o se aplica a ela. 


\begin{tabular}{|c|c|}
\hline Masculinas & Femininas \\
\hline Corajoso, Forte, Rígido, Viril, Sério & Meigo, Romântico, Orgânico, Frágil, Sensível \\
\hline
\end{tabular}

Tabela 4: Estereótipos de Gênero. Fonte: Autores, 2018.

Uma outra pergunta, direcionada aos participantes, diz respeito a qual público eles acreditam que essa peça é destinada. Com efeito, a terceira questão refere-se ao que levou o participante a pensar que o produto é destinado a determinado público (cores, formas, imagens, nome do produto ou marca etc.). Essas respostas podem enriquecer a análise, fundamentando com as afirmações a respeito de qual apelo retórico está reforçando ou questionando estereótipos de gênero.

Para melhor visualização dos resultados, recomenda-se que se faça representações visuais dos resultados obtidos nas pesquisas (ex. gráficos gerados na plataforma Google Forms). A tabela abaixo (Tabela 5) sintetiza o conteúdo do formulário proposto aos participantes.

\begin{tabular}{|c|c|}
\hline PERGUNTAS & RESPOSTAS \\
\hline $\begin{array}{c}\text { Assinale as palavras que, para você, } \\
\text { descrevem ou se aplicam à amostra observada } \\
\text { (você pode selecionar mais de uma opção): }\end{array}$ & $\begin{array}{c}\text { Corajoso / frágil / rígido / viril / meigo / sério } \\
\text { / romântico / orgânico / forte / sensível }\end{array}$ \\
\hline $\begin{array}{c}\text { Para você, essa peça foi feita para pessoas de } \\
\text { qual gênero? }\end{array}$ & Masculino / feminino / ambos / outro (qual?) \\
\hline $\begin{array}{c}\text { Quais elementos levaram você a pensar que a } \\
\text { peça foi feita para esse público? (você pode } \\
\text { selecionar mais de uma opção) }\end{array}$ & $\begin{array}{c}\text { Cores / ilustrações / tipografia / texto / marca } \\
\text { (logo) / nome do produto ou da marca / } \\
\text { formas / fotografia / outro (o que?) }\end{array}$ \\
\hline
\end{tabular}

Tabela 5: Questionário. Fonte: Autores, 2018.

\section{Parte 2: Estratégias Retóricas}

Nesta etapa ocorre a análise do uso das estratégias retóricas. Para isso são adotadas as definições propostas por Emanuel (2017) de Ethos, Pathos e Logos, buscando na amostra elementos que possam identificar determinado apelo retórico. Entende-se que cada peça pode conter mais de uma estratégia, e que o designer pode fazer uso delas de maneira intencional ou não.

Estipulou-se, para o modelo três, possíveis apelos para cada estratégia (Tabela 6). O(a) pesquisador(a) deve selecionar, em forma de check-list, aqueles apelos que aparecem na amostra analisada, além de descrever brevemente de que maneira esse apelo aparece na peça.

\begin{tabular}{|c|c|c|}
\hline Ethos & Pathos & Logos \\
\hline $\begin{array}{c}\text { Credibilidade, tradição, } \\
\text { honestidade. }\end{array}$ & $\begin{array}{c}\text { Emoção, lembrança, } \\
\text { analogia. }\end{array}$ & $\begin{array}{c}\text { Didatismo, evidência, } \\
\text { exemplo. }\end{array}$ \\
\hline
\end{tabular}

Tabela 6: Estratégias retóricas e apelos. Fonte: Autores, 2018.

\section{Diagnóstico}

O diagnóstico é feito com as conclusões e resultados combinados da Investigação e Análise. O(a) pesquisador(a) responde as perguntas da etapa final, elencadas abaixo, marcando no check-list a opção que corresponde aos resultados obtidos anteriormente. 
- A peça analisada reforça ou questiona estereótipos a respeito da categoria de gênero que incorpora?

\section{[ ] Reforça [ ] Questiona [ ] Outro:}

- Qual foi argumento/estratégia/apelo retórico mais evidente ao traduzir esse estereótipo ou provocação?

\section{[ ] Ethos [ ] Logos [ ] Pathos}

\section{Aplicação-teste do modelo}

A fim de verificar o funcionamento do modelo, se conseguia corresponder aos objetivos traçados e também observar a qualidade de sua aplicabilidade, fez-se uma aplicação-teste, utilizando cinco amostras de diferentes áreas do design gráfico, agrupadas na figura abaixo (Figura 7).
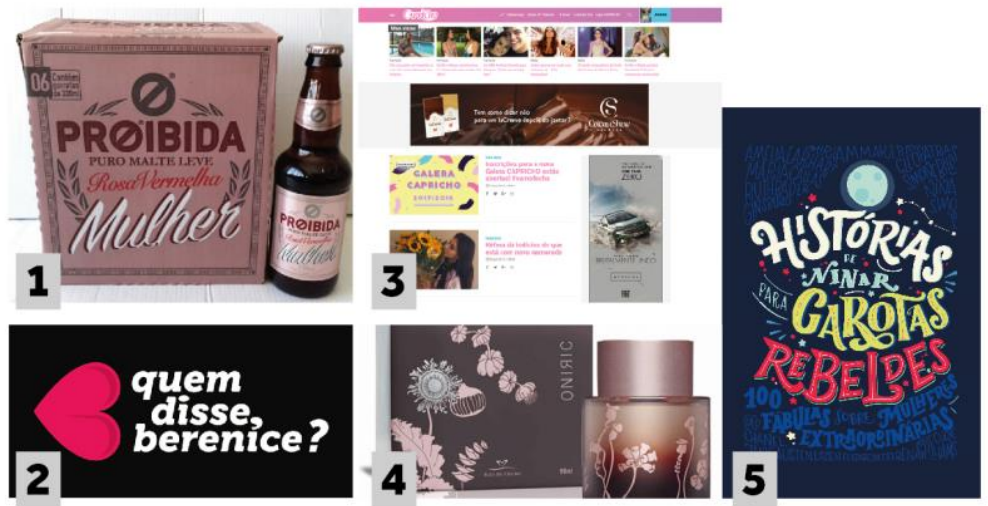

Figura 7: Amostras analisadas. Fonte: [1] https://goo.gl/mn41Px [2] https://goo.gl/spBYXf

[3] https://goo.gl/VAKCNs [4] https://goo.gl/TQubmW [5] https://goo.gl/EhDGrt. Acesso em: 14 jul. 2018.

Todas as amostras são peças de design destinadas ao público feminino, permitindo assim comparar a diferença na percepção e análise de cada uma das amostras pelos seus aspectos verbais e visuais. A seleção foi feita com base em diversos critérios, pois a intenção era explorar a versatilidade do modelo e a sua atuação em diversos produtos. Houve, no entanto, uma preferência por artefatos nacionais - com excessão a amostra 5, que se trata da versão brasileira de uma publicação estadunidense - e também que tivessem algum destaque: seja na mídia, através de premiação ou citação em catálogos, seja no seu segmento de mercado ou, ainda, na proposta de questionar ou subverter estereótipos de gênero. Na tabela abaixo (Tabela 7), estão apresentados os critérios de seleção de cada item.

\begin{tabular}{|c|c|}
\hline AMOSTRA & CRITÉRIOS DE SELEÇÃO \\
\hline 1- Embalagem: Cerveja Proibida Mulher & $\begin{array}{c}\text { Peça teve destaque na mídia por ser } \\
\text { classificada, por alguns consumidores, } \\
\text { como machista e preconceituosa. }\end{array}$ \\
\hline 2 - Identidade visual: Quem disse Berenice? & $\begin{array}{c}\text { Marca brasileira. A proposta da } \\
\text { empresa é diferente da maioria das } \\
\text { outras que trabalham com maquiagem, } \\
\text { e possui também uma proposta de } \\
\text { design diferenciada. }\end{array}$ \\
\hline
\end{tabular}

Estudos em Design | Revista (online). Rio de Janeiro: v. 28 | n. 1 [2020], p. 06 - 26 | ISSN 1983-196X 


\begin{tabular}{|c|c|}
\hline 3 - Web: Site Revista Capricho & $\begin{array}{c}\text { A Capricho ainda é o meio editorial } \\
\text { mais famoso para o público feminino } \\
\text { adolescente, e o site, um dos portais } \\
\text { mais acessados pelas adolescentes. }\end{array}$ \\
\hline 4 - Embalagem: Perfurme Oniric & $\begin{array}{c}\text { Aparece no catálogo Anatomia do } \\
\text { Design (CONSOLO, 2009). A } \\
\text { descrição do projeto relata que se trata } \\
\text { de um reposicionamento da empresa, } \\
\text { para se aproximar do público } \\
\text { feminino. }\end{array}$ \\
\hline 5 - Capa: Histórias de Ninar para Garotas Rebeldes & $\begin{array}{c}\text { Lançamento atual e com proposta de } \\
\text { empoderamento feminino. O objetivo } \\
\text { é verificar se o design é lido de forma } \\
\text { a questionar os estereótipos, para além } \\
\text { do conteúdo textual. }\end{array}$ \\
\hline
\end{tabular}

Tabela 7: Critérios de seleção das amostras. Fonte: Autores, 2018.

O teste com os usuários foi realizado por meio de um formulário online, no qual as cinco amostras foram avaliadas, uma de cada vez, por todos os participantes. Participaram, da pesquisa, vinte pessoas: dez homens e dez mulheres, de cinco faixa etárias diferentes, sendo elas: 15 a 25, 25 a 35, 35 a 45, 45 a 55 e 55 a 65 anos, buscando manter a variedade de perspectivas.

Com os resultados obtidos, foram elaboradas representações gráficas (Figura 8). Por meio da observação dessas representações, foi possível identificar as tendências para determinados estereótipos de gênero, bem como alguns elementos que ajudam a especificar quais os apelos retóricos, que tiverem destaque. 


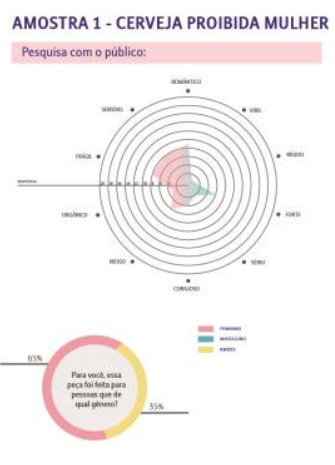

AMOSTRA 2 - QUEM DISSE, BERENICE? Pesquisa com o público:
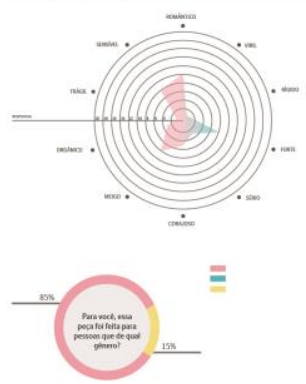

CORES NOME DO PRODUTO

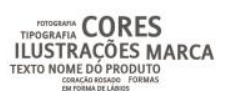

FOTOGRAFIA CORES NOMEDO ILUSTRAÇÕES

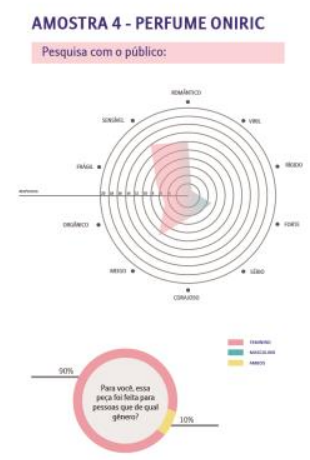

AMOSTRA 5 - HIST. DE NINAR PARA GAROTAS REBELDES

AMOSTRA 5 - HIST. DE NINAR PA

AMOSTRA 3 - SITE REVISTA CAPRICHO
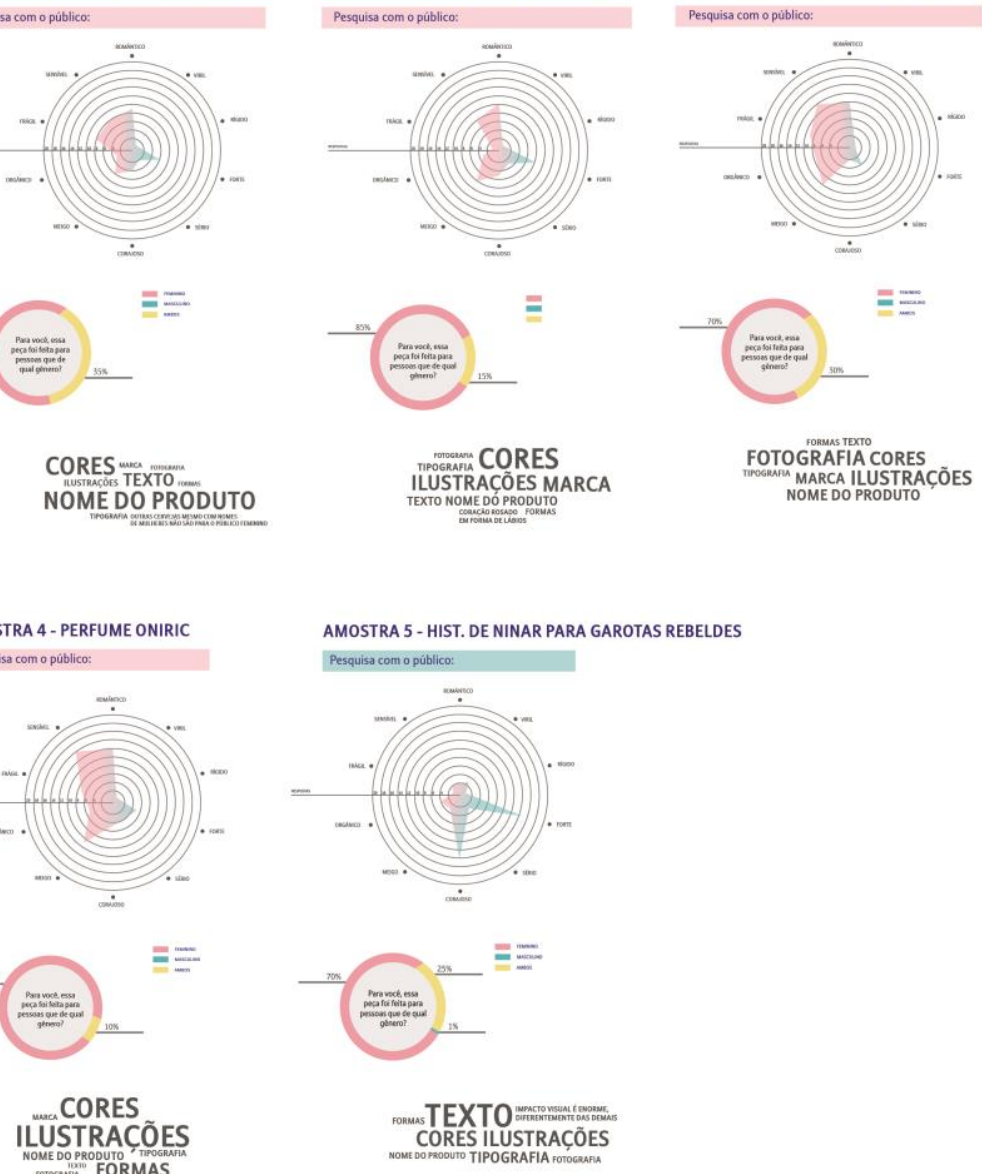

Figura 8: Comparação dos resultados da pesquisa com o público. Fonte: RATI, 2017, p. 86-87.

Para ilustrar a aplicação completa e individual do modelo, escolheu-se a análise da amostra 4, embalagem do perfume Oniric da empresa Água de Cheiro (Figura 9), que segue abaixo:

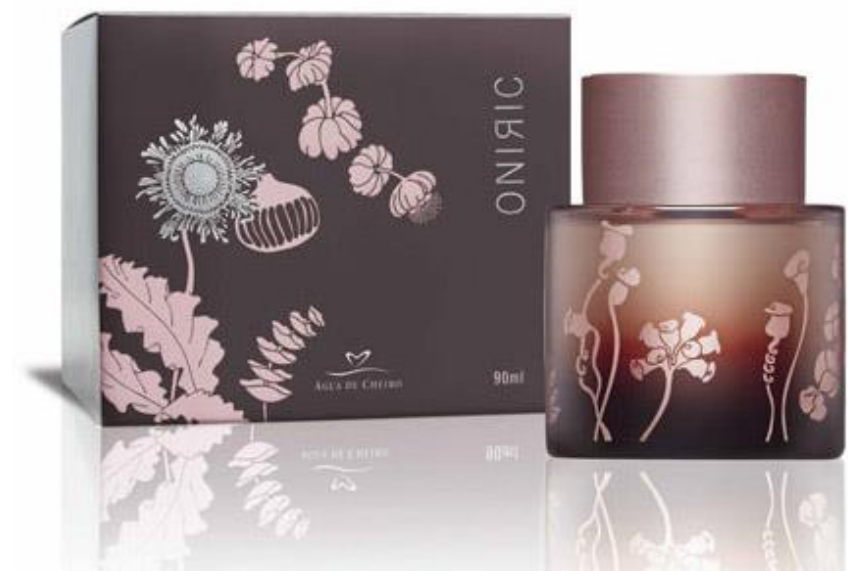

Figura 9: Amostra 4 (embalagem) Perfume Oniric.

Fonte: https://goo.gl/TQubmW. Acesso: 14 de jul. de 2017. 


\section{Seleção}

Como já mencionado, escolheu-se trabalhar com peças voltadas para o público feminino, sendo este o principal recorte feito. No caso do perfume Oniric, outro critério de seleção foi a menção no catálogo Anatomia do Design (CONSOLO, 2009), cuja proposta era apresentar "as articulações contemporâneas do design gráfico, seus enfrentamentos cotidianos e sua capacidade de gerar sistemas comunicativos por meio de simbologias" (p. 25). O projeto do perfume Oniric passou por uma avaliação de profissionais da área, e também se encaixou nos critérios do cátalogo, que envolvia a dimensão cultural do design. Por isso, é uma amostra interessante para ser analisada, já que uma peça mencionada nesse tipo de material geralmente é considerada de boa qualidade, inovadora ou que proponha novas perspectivas. $\mathrm{Na}$ tabela abaixo (Tabela 8), pode-se observar a amostra selecionada, o tipo e o critério de seleção.

\begin{tabular}{|c|c|c|}
\hline NOME & TIPO & CRITÉRIO DE SELEÇÃO \\
\hline $\begin{array}{c}\text { Perfume } \\
\text { Orinic }\end{array}$ & Embalagem & $\begin{array}{c}\text { Aparece no catálogo Anatomia do Design (CONSOLO, 2009, p. 45). } \\
\text { A descrição do projeto relata que se trata de um reposicionamento } \\
\text { da empresa para se aproximar do público feminino. }\end{array}$ \\
\hline
\end{tabular}

Tabela 8: Seleção. Fonte: Autores, 2018.

\section{Investigação}

O perfume da marca Água de Cheiro é um projeto de Mariana Hardy. No catálogo, a descrição do projeto relata que se trata de um reposicionamento da empresa para se aproximar do público feminino. $\mathrm{O}$ realease da empresa a respeito deste produto o descreve como sendo direcionado a mulheres delicadas, românticas e modernas, associando-o também à ideia dos sonhos, um mundo abstrato, onde as formas e cores podem ser moldadas de acordo com a vontade da mulher (COSMETICANEWS, 2013). Na tabela abaixo (Tabela 9), aprenta-se a síntese dos valores que o projeto gráfico do perfume busca transmitir, de acordo com as informações do catálogo e da empresa.

\begin{tabular}{|c|c|}
\hline VALORES DA MARCA OU PROJETO GRÁFICO & LANÇAMENTO \\
\hline $\begin{array}{c}\text { Mulheres delicadas, românticas e modernas. Os sonhos, um mundo abstrato } \\
\text { onde as formas e cores podem ser moldadas de acordo com a vontade da } \\
\text { mulher. }\end{array}$ & 2000 \\
\hline
\end{tabular}

Tabela 9: Investigação. Fonte: Autores, 2018.

\section{Análise}

Parte 1 - Estereótipos 
As figuras abaixo são representações gráficas, geradas a partir dos dados obtidos nas respostas dos participantes, no formulário online (supracitado na Tabela 5), a respeito da amostra 4.

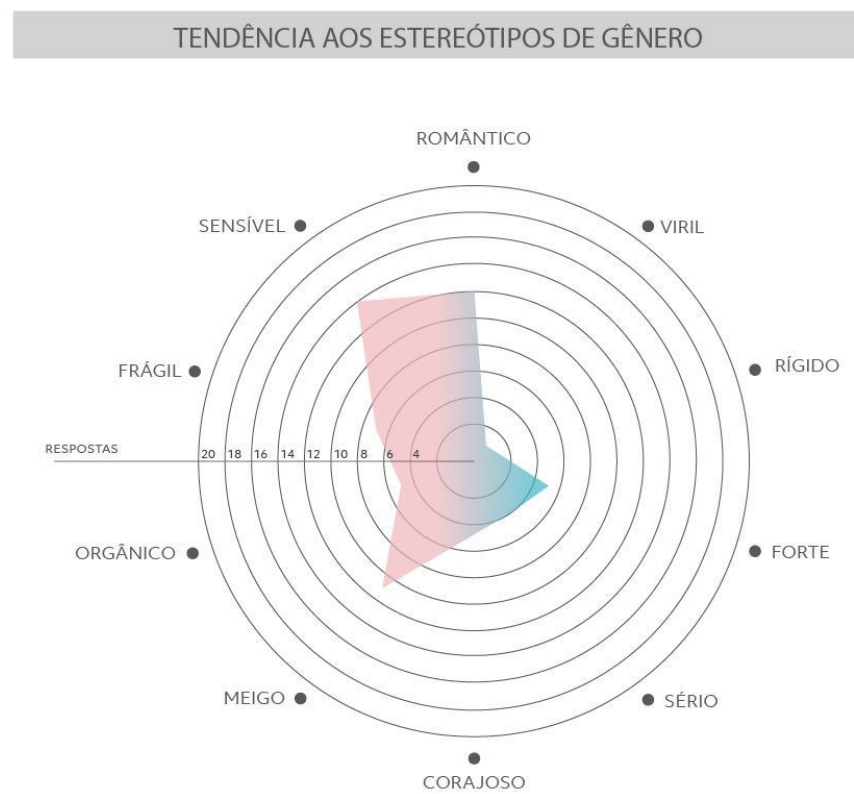

Figura 10: Tendência aos estereótipos de gênero - Perfume Oniric. Fonte: RATI, 2017, p. 79.

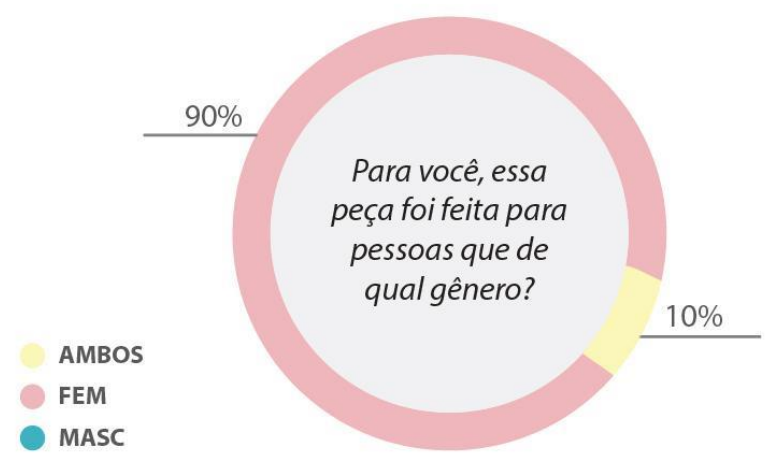

Figura 11: Recorte de público alvo - Perfume Oniric. Fonte: RATI, 2017, p. 80. 


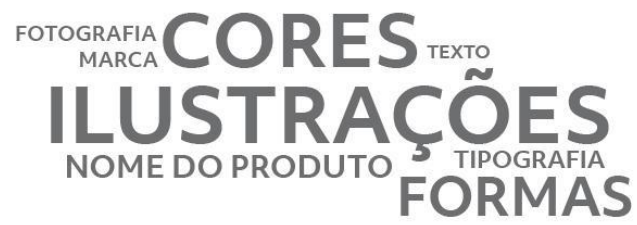

Figura 12: Elementos que caracterizam o recorte de gênero - Perfume Oniric. Fonte: RATI, 2017, p. 80.

\section{Parte 2 - Estratégias Retóricas}

Abaixo (Tabela 10), apresenta-se um formulário da análise sobre as estratégias retóricas utilizadas na peça analisada. A influência da estratégia pathos é percebida através do apelo à emoção e às lembranças. Isto foi observado, pelos analisadores, nas ilustrações de flores e nas formas orgânicas decorativas presentes na embalagem.

\begin{tabular}{|c|c|c|}
\hline \multicolumn{3}{|c|}{ Quais os apelos presentes na peça? } \\
\hline ETHOS & PATHOS & LOGOS \\
\hline credibilidade [ ] & emoção [x] & didatismo [ ] \\
\hline tradição [ ] & lembranência [ ] \\
\hline honestidade [ ] & analogia [ ] & exemplo [ ] \\
\hline \multicolumn{3}{|c|}{ De que maneira isso aparece? } \\
\hline & $\begin{array}{l}\text { Nas ilustrações de flores, } \\
\text { cores e formas presentes. }\end{array}$ \\
\hline
\end{tabular}

Tabela 10: Análise - Parte 2. Fonte: Autores, 2018.

\section{Diagnóstico}

\begin{tabular}{|c|c|}
\hline $\begin{array}{c}\text { A peça analisada reforça ou questiona } \\
\text { estereótipos a respeito da categoria de gênero } \\
\text { que incorpora? }\end{array}$ & $\begin{array}{c}\text { Qual ou quais foram as estratégias/apelos } \\
\text { retóricos mais evidentes ao traduzir esse } \\
\text { estereótipo ou provocação? }\end{array}$ \\
\hline Reforça $[\mathrm{x}]$ & Ethos [ ] \\
\hline Questiona [ ] & Pathos [x] \\
\hline Outro: & Logos [ ] \\
\hline
\end{tabular}

Tabela 11: Diagnóstico. Fonte: Autores, 2018. 
Nota-se, através da pesquisa com o público (Figura 10), que os valores da marca foram transmitidos através do projeto gráfico, o qual corrobora com estereótipos do gênero feminino, de acordo com a palavras selecionadas pelas pessoas que participaram. Além disso, os elementos que mais caracterizam gênero são as cores, as ilustrações e as formas (Figura 12), características que remetem à estratégia retórica pathos, como um apelo à emoção e às lembranças do observador.

\section{Considerações finais e desdobramentos}

Neste artigo estudou-se a respeito dos estereótipos de gênero e como eles aparecem no design gráfico mediante as estratégias retóricas ethos, logos e pathos. O estudo serviu de base para o desenvolvimento de um modelo analítico, que busca verificar se uma peça de design reforça ou questiona determinado estereótipo de gênero.

Como visto na fundamentação teórica, as mulheres configuram a categoria que mais sofre com estereótipos que a elas são atribuídos, indicando inferioridade e opressão social. Tais estereótipos são naturalizados por um processo de socialização que forma os indivíduos e suas concepções sobre o que é masculino ou feminino.

Observou-se que o design se relaciona com os mais diversos aspectos da sociedade em que está inserido, e que, em sua articulação da linguagem visual, serve-se de estratégias retóricas para comunicarse. Sendo assim, o modelo de análise pode ser uma ferramenta de auxílio no estudo desses aspectos, trazendo um modo de averiguar sobre como se produz design voltado para determinado gênero; se a abordagem utilizada é coerente, se reforça ou não conceitos estereotipados que podem ser nocivos, ou até mesmo violentos. Com efeito, trata-se de refletir sobre como o design também contribui para a formação da identidade de gênero dos indivíduos por meio da identificação, consciente ou irrefletida, do que é considerado masculino ou feminino.

Tanto as pesquisas quanto o próprio modelo analítico merecem desdobramentos futuros posto que há espaço para adaptações e aprimoramentos, bem como a necessidade de que o modelo seja aplicado em outros contextos e testado outras vezes para ser aprimorado. Sugere-se, por exemplo, que também se aplique o modelo para avaliar amostras voltadas ao público masculino, para verificar se essas peças também recorrem a estereótipos de gênero. Outra possível aplicação é numa linha de produtos ou peças inteiras ou, ainda, na comparação entre os layouts de um determinado produto de várias marcas diferentes. Também é possível usar o modelo para avaliar amostras que não tenham recorte de gênero específico, apenas para verificar se ocorre alguma tendência e para quais estereótipos.

Entende-se as várias possibilidades de desdobramentos futuros como pontos positivos e indicativos de uma área muito rica para ser estudada. Mas, principalmente, vislumbra-se uma contribuição preliminar tanto às questões de design quanto às de gênero, e os pontos onde se encontram. Espera-se que esse trabalho possa não só agregar ao avanço desses estudos, mas também fomentar uma prática consciente de design gráfico, não mais fazendo apelo a discursos e representações injustas, e até mesmo opressoras, às mulheres.

\section{Referências}

ALMEIDA JUNIOR, Licinio de; NOJIMA, Vera Lúcia. Retórica do design gráfico: da prática à teoria. São Paulo: Blucher, 2010.

ALVES, Branca Moreira; PITANGUY, Jacqueline. O que é feminismo?. São Paulo: Editora Brasiliense. 1985.

AMÂNCIO, Lígia. As assimetrias nas representações do género. Revista Crítica de Ciências Sociais, Coimbra, n. 34, Fevereiro, 1992. 
BARNARD, Malcolm. Graphic design as communication. Nova Iorque: Routledge. 2005.

BARROS, Bruno. Design, linguagem e retórica. Estudos em Design, v. 17, n. 02. Rio de Janeiro: aend-br, 2009. Disponível em: 〈https://www.eed.emnuvens.com.br/design/article/view/38>. Acesso em: 15 mai. 2017.

BONSIEPE, Gui. Design, cultura e sociedade. São Paulo: Blucher, 2011.

BUCHANAN, R. Rethoric, Humanism and Design. In: BUCHANAN, R; MARGOLIN, V. (Eds.) Discovering Design: Explorations in Design Studies. Chicago: The University of Chicago Press, 1995, p. 23-66.

BUCKLEY, Cheryl. Made in patriarchy: toward a feminist analysis of women and design. Design Issues, V. 3, n.2. MIT Press Publication. Autumm, 1986. p. 3-14. Disponível em: <www.jstor.org/stable/1511480>. Acesso em: 07 mai. 2017.

BUTLER, Judith. Problemas de gênero: feminismo e subversão da identidade. 13 ed. Rio de Janeiro: Civilização Brasileira, 2017.

CAMPOS, Fábio Ferreira da Costa; LEITE, Iracema Tatiana; WAECHTER, Hans da Nóbrega. A representação do gênero no design. In: Anais do $9^{\circ}$ Congresso Brasileiro de Pesquisa e

Desenvolvimento em Design. São Paulo: AEND-Brasil/Anhembi Morumbi, 2010. Disponível em: <https://pt.scribd.com/document/201061497/A-representacao-do-genero-no-design>. Acesso em: 01 mai. 2017.

CONSOLO, Cecília (org.). Anatomia do Design: uma análise do design gráfico brasileiro. São Paulo: Blucher, 2009.

COSMÉTICA NEWS. Água de cheiro apresenta Oniric. Disponível em:

<http://www.cosmeticanews.com.br/leitura.php?id=188>. Acesso em: 13 ago. 2017.

DOBSON, Terry; DOBSON, Saeri Cho. Tip of the icon: Socially Simbolic Indexal Signage.

Dialectic, v. 1, n. 1, p. 61-90, 2017. Disponível em:

<http://dx.doi.org/10.3998/dialectic.14932326.0001.106>. Acesso em: 30 jul. 2017.

DUBBERLY, Hugh. How do you design? A compendium of models. São Francisco: Dubberly Design Office, 2004.

EMANUEL, Bárbara. A retórica da Interação, 2017. Tese (Doutorado) - Escola Superior de Desenho Industrial (Universidade do Estado do Rio de Janeiro). Rio de Janeiro: ESDI-UERJ, 2017. FOUCAULT, Michel. A ordem do discurso. São Paulo: Edições Loyola, 2014.

A arqueologia do saber. Rio de Janeiro: Forense Universitária, 2008.

FRASCARA, Jorge. Diseño grafico para la gente. Buenos Aires: Ediciones Infinito, 2000.

HORN, Robert E. Visual Language: Global Communication for the 21st Century. Bainbridge Island, Washington: MacroVU, 1998.

KISTMANN, V. B. Interdisciplinaridade: questões quanto à pesquisa e à inovação em design. Estudos em Design (Online), v. 2, p. 81-99, 2014.

LOURO, Guacira Lopes. Gênero, sexualidade e educação: Uma perspectiva pósestruturalista. 16. ed. Petrópolis, RJ: Vozes, 2014.

ONO, Maristela. Design e cultura: uma sintonia essencial. Curitiba: Edição da Autora, 2006.

ORTNER, Sherry B. Is female to male as nature is to culture? In: ROSALDO, M. Z.; LAMPHERE, L. (eds.). Woman, culture and society. Stanford, CA: Stanford University Press, 1974, p. 68-87.

RATI, Bianca Mendes. Estereótipos de gênero e apelos retóricos no design gráfico: um modelo de análise. Trabalho de Conclusão de Curso (Design Gráfico). Curitiba:

Universidade Federal do Paraná, 2017. 
SEGATO, Rita L. Las estructuras elementales de la violencia. Buenos Aires:

Universidade Nacional de Quilmes, 2003.

SOUZA LEITE, João de. O discurso do design gráfico como polifonia. Estudos em Design, v. 5, n. 1, p. 59-68, 1996. Disponível em:

<http://www.academia.edu/5202829/O_discurso_do_design_gr\%C3\%A1fico_como_polifon ia>. Acesso em: 01 mai. 2017.

\section{Sobre os autores}

\section{Bianca Mendes Rati}

É graduada em Design Gráfico pela Universidade Federal do Paraná. Interessada nas relações do design com gênero, educação e história.

biancamrati@gmail.com

\section{Marcos Namba Beccari}

Doutor em Filosofia da Educação pela USP, designer gráfico e Mestre em Design, ambos pela UFPR. Professor Adjunto atuante no curso de Design Gráfico e no Programa de PósGraduação em Design da UFPR. Trabalha principalmente com os temas Filosofia do Design, Crítica em Design, Estudos Discursivos, Estética e Visualidades.

contato@marcosbeccari.com 